\title{
DETERMINING THE POTENTIAL SUCCESS OF CONSERVATIVE TREATMENT OF ROTATOR CUFF IMPINGEMENT
}

\section{J Sklaar BSc Physiotherapy \\ (Witwatersrand). Honorary \\ lecturer, Physiotherapy, University \\ of the Witwatersrand. Private \\ Practitioner}

\section{INTRODUCTION}

A clinical test is proposed which will end the dilemma of whether conservative treatment will be of value in patients diagnosed with rotator cuff impingement syndrome.

To date there are no conclusive invasive or non-invasive tests to diagnose the stage of impingement eg. arthrogram will only be positive in a full thickness tear. If the muscle is $99.9 \%$ torn the arthrogram result will be negative.

It is important to diagnose progressive impingement in order to prevent a continuum of the pathology. The prognosis after a decompression or repair of a small tear, is much more favourable than if the tear is allowed to enlarge.

\section{METHOD OF TEST}

An objective test, called the " $\mathrm{S}$ " test, is described which is based on clinical observation which is diagnostic and prognostic of early supraspinatus tears.

The physiotherapist and patient stand facing each other, with their arms at their sides. Elbows are flexed to $90^{\circ}$ and forearms are midway between supination and pronation.

The physiotherapist places her hands laterally and proximally to the patients wrists and bilaterally applies a medially directed force, while the patient statically resists this force. This tests the static resistance of external rotation and must be taken to breaking point to pick up small changes between the two arms.

The test is considered positive if there is even the slightest weakness or pain and weakness of the one arm compared to the other.
If a patient with signs and symptoms of a Rotator Cuff lmpingement syndrome is treated conservatively and recovers fully, but the " $S$ " test remains even slightly positive, then it is proposed that this is indicative of an early supraspinatus tear, partial or complete. Also if the " $\mathrm{S}$ " test gets weaker, then it is proposed that this is indicative of a progressive tear. In either case, further tests are necessary as operative intervention may be indicated rather than conservative treatment at this stage.

A positive "S" test signifies a supraspinatus tear.

The arm is in neutral for this test and therefore when tension is applied it tests the integrity of the supraspinatus muscle itself, as opposed to the impingement tests which are all done with the arm in $>90^{\circ}$. This sandwiches the muscle between the acromion, coraco-acromial ligament and humerus. Any stage of impingement will test positive regardless of whether there is true muscle damage or just an oedema or haemorrhage. There is no way of diagnosing the stage of impingement with the standard impingement tests.

\section{DISCUSSION}

We have observed that a positive "S" test is indicative of supraspinatus pathology, and this gives rise to two questions: 1. Besides its traditional role as an abductor is supraspinatus an external rotator in neutral?

2. In addition or alternatively, does a torn supraspinatus render an intact infraspinatus biomechanically inefficient.

Calliett (1981) viewed the action of supraspinatus in a unique way ${ }^{1}$.

He looked at the supraspinatus from a superior view and made the interesting observation that the supraspinatus runs posterior to the axis of rotation of the humerus, on its way to attach to the greater tuberosity. Therefore when it contracts it must externally rotate the humerus.
With the help of an orthopaedic surgeon we conducted a cadaver study and confirmed Calliett's observation. We also detached the muscle from the supraspinatus fossa and pulled on the muscle in order to simulate a contraction. We noted a small but definite movement of the arm into external rotation, this was limited by the fact that the cadaver was very rigid. Biomechanically therefore, it is possible for the supraspinatus to be an external rotator. We then decided to simulate a supraspinatus tear. At operations we had noticed that with supraspinatus tears the infraspinatus fell into a postero-inferior position. We felt that because anatomically the tendons blended into one cuff, if the supraspinatus was disrupted then by virtue of this fact the attachment of infraspinatus will be loosened and therefore weakened. Therefore the answer to the second question, a tear of supraspinatus can render an intact infraspinatus biomechanically inefficient.

Post et al (1983), reviewed 59 patients with rotator cuff tears confirmed at operations and found that patients with severe external rotator muscle weakness, loss of good elevation and increased crepitus had larger tears ${ }^{2}$.

Brems (1988) reported having done a study using a hand held digital strength analyser and found that external rotator weakness was proportional to the size of the tear ${ }^{3}$.

Neviaser (1971) reviewed 42 patients who had confirmed rotator cuff tears and found that the predominant presenting feature was pain ${ }^{4}$. He found in these patients that there was no significant weakness in abduction and there was an absence of a positive drop-arm sign. All these studies supported our observations. 1. The " $S$ " test is diagnostic of supraspinatus pathology.

2. The weakness of the "S" test is proportional to the size of the supraspinatus tear.

3. Static resisted/active abduction is not conclusive in tears of supraspinatus. 


\section{DISCOVER AMERICA}

500 years ago Columbus discovered America.

Today, Action Medical is helping South African physiotherapists and occupational therapists to make great discoveries of their own.

You may be interested in exploring the country, working on short assignments in a variety of locations on our Discover America program, which in addition to an excellent salary, offers you free housing, subsistence allowance, medical and dental insurance and a full range of other benefits.

Or if it suits you and your family better to make a career move and settle in the state or city of your choice, you will be able to benefit from our US Placement Strategy, in which we conduct

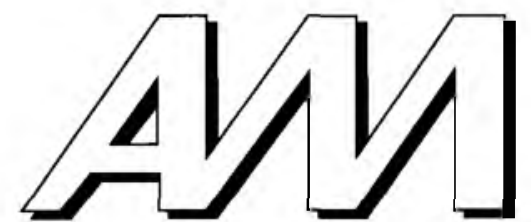
$\frac{\text { ACTION MEDICAL }}{\text { SOUTH AFRICA }}$

PO Box 36414, Glosderry 7702 Tel/fax: 021614048 (24 hrs) a personal search on your behalf to find the employment opportunity most suited to your particular preferences.

Our extensive experience as an independent recruitment consultancy, and our commitment to a personal and comprehensive relocation service, are your guarantee of the widest possible range of employment options, and a smooth and successful transition to your new life in America.

Let Action Medical link you to a New World of opportunity - call Juliana Canham now on 021614048 or send us your CV today.

By all accounts, Columbus' voyage of discovery was long and arduous.

But then he didn't have

Action Medical to help him.

WORLDWIDE HEAD OFFICE: 3 RABY PLACE, BATH BA2 4EH,UNITED KINGDOM TEL: + 441225447445 FAX: + 441225446161 (24 HOURS)

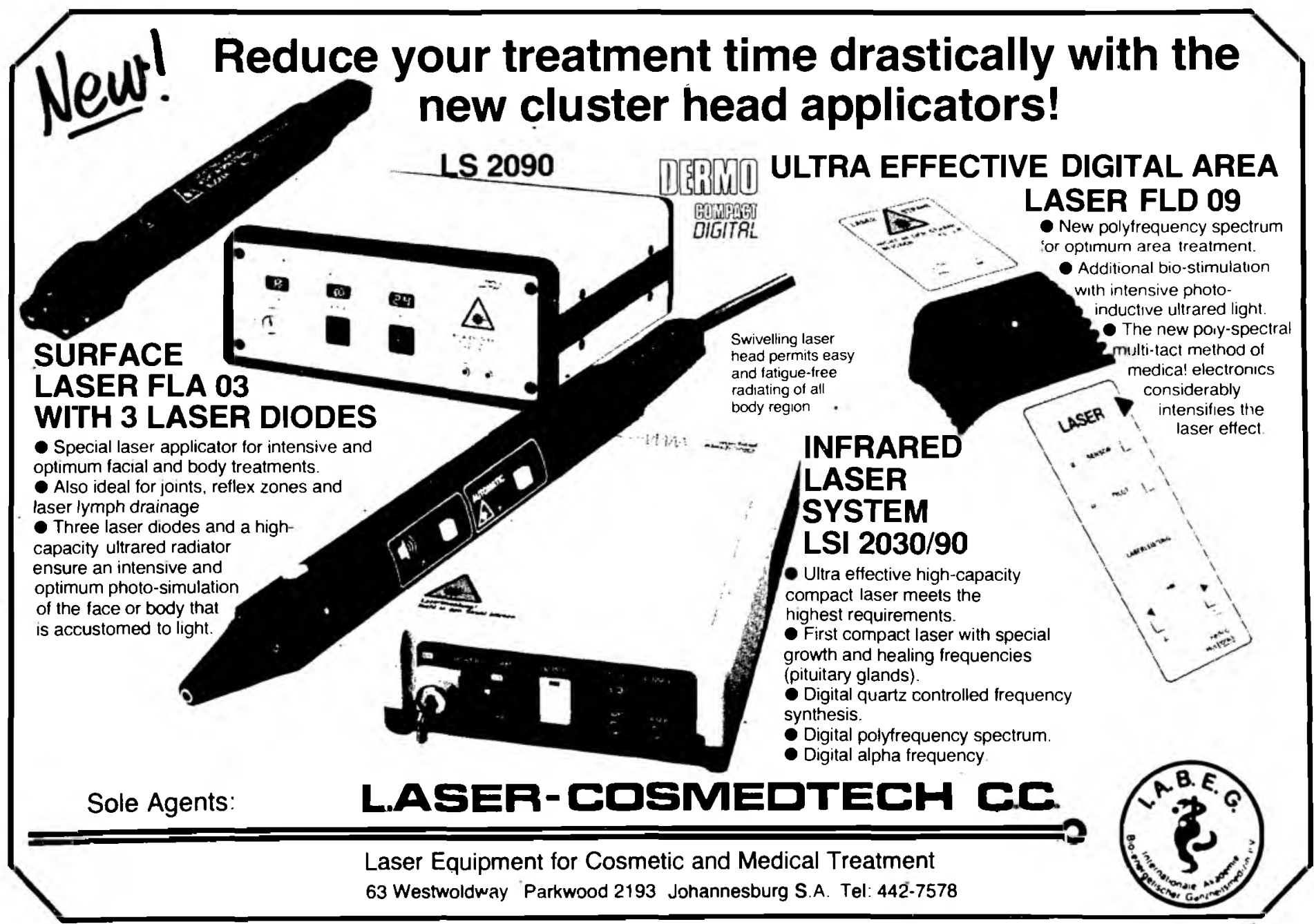




\section{STAGES OF IMPINGEMENT}

Neer (1983) has classified three stages of impingement which are similar to the stages of pathology in all joints 5 . We have also added the fourth stage which is a clinical entity peculiar to the gleno-humeral joint described by Neer et al ${ }^{6}$.

\section{Stage One - Oedema and Haemorrhage}

The patients with stage one are usually younger than 25 years and present with an arc of pain after excessive overhead use in sport or work. The treatment is conservative and there is a good prognosis for total reversal.

\section{Stage Two - Fibrosis and Tendinitis/ Adhesions}

Stage two occurs with repeated episodes of mechanical impingement. The bursa and tendons become thickened and fibrotic and the problem magnifies. It usually occurs between 25 and 40 years. The shoulder functions satisfactorily for light activity but becomes painful locally after overhead use. Surgery is done only if conservative treatment fails.

\section{Stage Three - Bone Spurs and Tendon Ruptures (Partial or complete)}

With further impingement wear, complete or incomplete tears of the rotator cuff and biceps tendon occur. Patients are almost exclusively older than 40 years. Bone changes may develop. The pain is referred distally and there is night pain. The success of conservative treatment at this stage is doubtful.

\section{Stage Four - Cuff Tear Arthropathy}

Full thickness tears of $4 \%$ will progress to a cuff tear arthropathy. This usually occurs in patients over 50 years. The patient presents with constant pain which is severe at night and a progressive disability. A cuff tear arthropathy results in severe disorganisation of the gleno-humeral joint with collapse of the humeral head and the treatment is shoulder replacement. In this case prevention is better than cure and perhaps with a diagnosed full thickness tear it is better to repair early. 1 am proposing that with the " $\mathrm{S}$ " test you will be able to diagnose an early stage 3 .

Although looking at the above it seems our dilemma was senseless as a simple decision can be made ie., stage 1 and 2 are treated by the physiotherapist and stage three and four need further investigation and probable surgery. This is deceptive.
As stated initially there are no tests (besides this one that $l$ am proposing) to accurately diagnose these stages. The symptoms and physical signs of all the stages overlap. Any one stage can present with signs and symptoms of the other stages. Neer states that surgeons often erroneously think that a tear has healed when it was a stage one ie. an oedema or haemorrhage. It is also possible to confuse a stage three that has settled for a stage one, thus partial or small tear can easily be missed.

\section{CONCLUSION}

If the "S test is positive and remains so despite all other signs and symptoms of a rotator cuff syndrome clearing with conservative treatment, then we are proposing that it is an accurate diagnostic and prognostic test of supraspinatus tears and that the patient must be sent to the orthopaedic surgeon for further investigation and probable surgery.

\section{REFERENCES}

1. Cailliet R. The Shoulder. F A Davis 1981;2:20.

2. Post $M$ et al. Rotator Cuff Tear. Clinical Orth and Related Research March 1983;173.

3. Brems J J. Rotator Cuff Tear: Evaluation and Treatment. Orthopedics 1988;2:1.

4. Neviaser J S. Ruptures of the Rotator Cuff of the Shoulder. Arch Surg May 1971;102:483485.

5. Neer C S. Impingement Lesions. Clinical Ortho and related Research, March 1983;173.

6. Neer C S, Craig E W, Hiroaki H. Cuff-Tear Arthropathy. J of Bone and Jnt Surg, December 1983;65A:9.

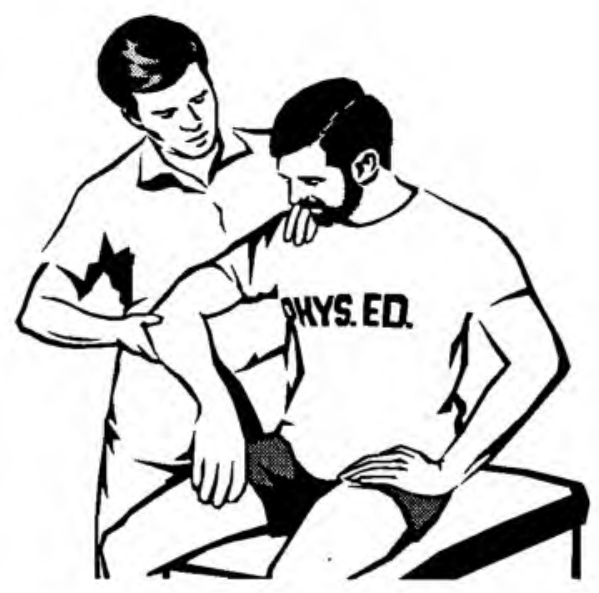

RESEARCH vs CONJECTURE A Letter to the Editor

This letter is written in reference to an article published in the November 1994 issue of the SA Journal of Physiotherapy.

This article is referred to as "research" by the author. I do not see this terminology being appropriate for an article which is based entirely on subjective notions and pure conjecture. No statistical evidence is presented and the author bases the validity of her training regimen on one case study only - that of Athlete B. Where references are used, they include one textbook dated 1991 to substantiate that water exercises are gaining "momentum" at present and references to the Akwa Letter (presumably a newsletter) can hardly be recognised as legitimate.

When describing the improvements made by the two case studies, the author does not inform the reader of any specific parameters by which the improvements in physical fitness were measured. Improvements in anaerobic capacity are also sited for Athlete B. How this was measured and to what extent the anaerobic capacity improved is similarly not described. These are just a few examples to illustrate why none of what is written in this article is of any value to the discerning professional.

Taking the above factors into account, the extrapolation that "water exercise is a crucial breakthrough in training sportsmen and women" cannot be made. Furthermore, the background section used to substantiate the physiological effects of water exercise is not referenced at all.

This article can hardly be regarded as professional literature. Is it not time that our journal started meeting international standards? In view of the above it is unlikely that I and probably other members of the profession would consider publishing in this journal in future.

Mr Michael Barker, Post-Graduate Student, Department of Physiotherapy, UniNOTE versity of the Witwatersrand

The Editor shares the concerns of the writer and welcomes any constructive criticism from our readers. See the Editorial for some clarification of the problems regarding publication. However, threatening to withhold submission of articles to our Journal will not help to improve standards and hopefully the writer will reconsider this option.

IC Beenhakker 